\title{
Performance of Petroleum Car Engines Around The Railway
}

\section{Performa Mesin Mobil Minyak Di Sekitar Rel Kereta Api}

\author{
Ah. Sulhan Fauzi ${ }^{1}$, Kuni Nadliroh ${ }^{2}$ \\ \{ sulhanfauzi@unpkediri.ac.id ${ }^{1}$, kuninadliroh@unpkediri.ac.id ${ }^{2}$ \} \\ Teknik Mesin, Universitas Nusantara PGRI Kediri
}

\begin{abstract}
The car accident while passing on the railroad tracks is not new anymore. Several assumptions emerged about the cause of the breakdown of the car. Some say it's because of the magnetic field that arises from the friction between railroad iron and railroad wheels. Various internet sites have discussed the problem of car accidents that often occur at train crossings, but do not include the cause of the accident. Logically, it is true that the friction between two metals will cause something that according to physics is called thermal energy in the form of heat. The heat generated by the friction of the railroad tracks and wheels is certainly not the cause of these accidents. In several previous studies, it was stated that the friction between the wheels and railroad tracks causes changes in the earth's magnetic field. The change in the earth's magnetic field is not yet known whether it affects the performance of a car engine. This research will look for the effect of changes in the earth's magnetic field on the performance of car engines. The engine performance under study is to compare car engine speed between car engine speed data due to changes in the earth's magnetic field with car engine speed data without the influence of changes in the earth's field using the $t$ test method for two paired samples. The results of the data test show that changes in the earth's magnetic field do not affect the performance of a car engine speed.
\end{abstract}

Keywords - car accident; friction; magnetic field; engine speed

\begin{abstract}
Abstrak. Kecelakaan mobil saat lewat di atas rel kereta api sudah bukan berita baru lagi. Beberapa asumsi muncul tentang penyebab mogoknya mobil tersebut. Ada yang bilang karena medan magnet yang timbul dari gesekan antara besi rel kereta api dan besi roda kereta api. Berbagai situs internet pernah menyinggung masalah kecelakaan mobil yang sering terjadi di perlintasan kereta api, tetapi tidak menyertakan penyebab kecelakaan tersebut. Secara logis memang benar kalau gesekan antara dua logam akan menyebabkan sesuatu. Sesuatu itu, menurut fisika disebut thermal energy berupa panas. Panas yang ditimbulkan akibat gesekan rel dan roda kereta api ini pastilah bukan penyebab dari kecelakaan-kecelakaan tersebut. Pada beberapa penelitian sebelumnya menyebutkan bahwa gesekan antara roda dan rel kereta api ini menyebabkan perubahan medan magnet bumi. Perubahan medan magnet bumi ini belum diketahui apakah berpengaruh terhadap kinerja mesin mobil. Penelitian ini akan mencari pengaruh perubahan medan magnet bumi tersebut terhadap kinerja mesin mobil. Kinerja mesin yang diteliti adalah membandingkan putaran mesin mobil antara data putaran mesin mobil akibat perubahan medan magnet bumi dengan data putaran mesin mobil tanpa pengaruh perubahan medan bumi dengan menggunakan metode uji T untuk dua sampel berpasangan. Hasil uji data menunjukkan bahwa perubahan medan magnet bumi tidak mempengaruhi kinerja putaran mesin mobil.
\end{abstract}

Kata Kunci - kecelakaan mobil; gesekan; medan magnet; putaran mesin

\section{Pendahuluan}

Setiap orang akan selalu melakukan perpindahan tempat dari satu tempat ke tempat lain untuk memenuhi kebutuhan hidupnya. Proses perpindahan tersebut bisa dilakukan dengan berjalan kaki atau menggunakan alat yang digerakkan oleh mesin, yang disebut dengan sarana transportasi. Sarana transportasi terbagi menjadi tiga bagian atau jalur, yaitu jalur darat, laut dan udara. Kereta api dan mobil merupakan salah satu sarana transportasi yang paling banyak digunakan pada jalur darat. Banyaknya penggunaan dua jenis sarana transportasi darat tersebut salah satunya ditandai dengan banyaknya berita yang melibatkan keduanya. Sepanjang tahun 2020, terhitung sejak awal tahun 2020 hingga awal bulan Oktober 2020, sudah tercatat 198 kecelakaan di perlintasan kereta api [1]. Kalau dibuat rata-rata setiap dua hari sekali terjadi kecelakaan yang melibatkan mobil dan kereta api. Penyebab pasti kecelakaan-kecelakaan tersebut belum bisa diketahui sampai saat ini. Beberapa asumsi muncul mengenai penyebab kecelakaan-kecelakaan tersebut, pihak PT KAI mengklaim bahwa penyebab kecelakaan itu karena human error atau sumber daya manusia (SDM) dari operator yakni mencapai $24 \%$. Disusul penyebab lainnya adalah faktor sarana $21 \%$ dan prasarana $10 \%$ sedangkan sisanya karena faktor pemakai jalan (pengemudi mobil atau motor) [2]. Muncul juga dugaan penyebab 
kecelakaan-kecelakaan tersebut adalah karena ada medan magnet di sekitar rel kereta api yang mengganggu kinerja mesin kendaraan bermotor [3, 4].

Medan magnet di sekitar rel saat kereta api melintas memang masih belum diketahui secara pasti kebenarannya. Beberapa penelitian menyebutkan terjadi di sekitar rel saat kereta api melintas adalah adanya perubahan medan magnet bumi [5, 6]. Secara normal medan magnet magnet bumi adalah $25-65 \mu \mathrm{T}$ [7, 8]. Pada penelitian sebelumnya didapatkan nilai medan magnet bumi di sekitar rel saat kereta api melintas mengalami perubahan paling rendah adalah 22,46 $\mu \mathrm{T}$, sedangkan nilai paling tinggi adalah 82,06 $\mu \mathrm{T}$ [9].

Kinerja mesin akan mengalami gangguan salah satunya ditandai dengan putaran mesin yang tidak stabil. Putaran mesin mobil pada keadaan mesin stasioner adalah sekitar $800 \mathrm{Rpm}$. Ketidakstabilan putaran mesin mobil bias terjadi karena gangguan beberapa faktor, pertama karena faktor usia dan intensitas pemakaian yang menyebabkan kondisinya menurun, kedua karena rusaknya beberapa komponen kelistrikan mobil seperti aki, alternator dan voltage regulator [10]. Bisa juga karena gangguan di system pembakarannya dan pengapiannya. Pada mobil berbahan bakar bensin, system pengapian mobil ini sangat dipengaruhi oleh induksi medan listrik yang ditimbulkan oleh busi sebagai pemantik pembakaran.

Pemagnetan suatu bahan oleh medan magnet luar disebut induksi. Induksi magnetik sering didefinisikan sebagai timbulnya medan magnetik akibat arus listrik yang mengalir dalam suatu penghantar. Oersted menemukan bahwa arus listrik menghasilkan medan magnetik [11]. Selanjutnya, secara teoritis Laplace menyatakan bahwa kuat medan magnetik atau induksi magnetik di sekitar arus listrik berbanding lurus dengan kuat arus listrik,panjang kawat penghantar dan berbanding terbalik dengan kuadrat jarak suatu titik dari kawat penghantar tersebut. Besarnya medan magnet yang dihasilkan dari kawat lurus beraliran listrik dapat dihitung dengan persamaan Biot-Savart [11].

$$
\begin{aligned}
& B=\frac{\mu_{o}}{2 \pi} \frac{I}{a} \\
& B=\text { kuat medan magnet }(\mathrm{T}) \\
& \mu_{o}=4 \pi \times 10^{-7}\left(\mathrm{~Wb} \cdot \mathrm{A}^{-1} \cdot \mathrm{m}^{-1}\right) \\
& I=\text { arus listrik }(\mathrm{A}) \\
& a=\text { jarak titik dengan kawat }(\mathrm{m})
\end{aligned}
$$

Gesekan antara rel dan roda kereta api yang terbuat dari besi diasumsikan dapat menghasilkan muatan listrik yang bergerak sehingga menimbulkan arus listrik (I), sehingga menimbulkan medan magnet (B) sesuai dengan jarak (a) disekitarnya.

\section{METODE}

Penelitian ini dilakukan pada rel kereta api di daerah sekitar kabupaten dan kota Kediri yang memiliki perlintasan kereta api diesel antar kota dan antar propinsi. Penelitian dilakukan dengan membandingkan data putaran mesin mobil pada ruang yang medan magnet buminya dibuat seperti saat kereta api melintas dengan data putaran mesin mobil pada keadaan normal. Data perubahan medan magnet di sekitar rel saat kereta api melintas paling rendah 22,46 $\mu \mathrm{T}$, sedangkan nilai paling tingginya 82,06 $\mu \mathrm{T}$ [5], sedangkan medan magnet bumi di sekitar rel saat tidak ada kereta api yang melintas adalah sekitar $45 \mu \mathrm{T}$. Alur penelitian bisa dilihat pada gambar 1 .

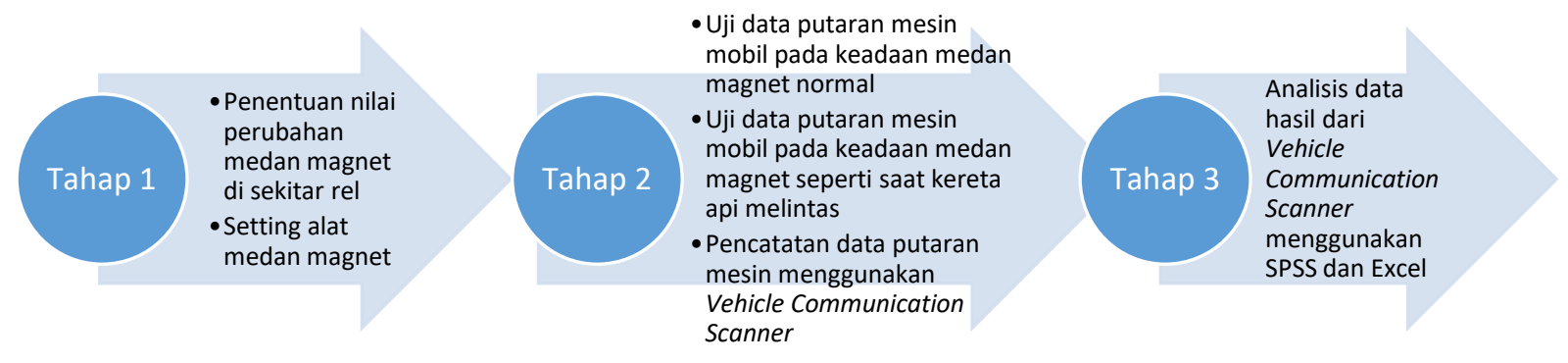

Gambar 1. Diagram alur penelitian

Penelitian pada tahap 1 bertujuan untuk membuat ruang/ keadaan sesuai dengan nilai medan magnet seperti saat kereta api melintas, dengan membuat alat sesuai persamaan (1), yaitu kawat penghantar berarus dengan variasi jarak 
kawat terhadap mesin mobil sehingga menghasilkan nilai medan magnet yang dibuat menjadi tiga yaitu $80 \mu \mathrm{T}, 50 \mu \mathrm{T}$ dan $20 \mu \mathrm{T}$, sesuai tabel 1. Sumber arus menggunakan aki mobil type NS40ZL dengan voltase 12 volt dan arus 40 ampere.

Tabel 1. Variasi medan magnet dengan perubahan jarak

\begin{tabular}{ccc}
\hline $\begin{array}{c}\text { Medan magnet } \\
(\boldsymbol{\mu} \mathbf{T})\end{array}$ & $\begin{array}{c}\text { Arus } \\
(\text { Ampere) }\end{array}$ & Jarak (meter) \\
\hline 20 & 40 & 0,4 \\
50 & 40 & 0,2 \\
80 & 40 & 0,1 \\
\hline
\end{tabular}

Pada tahap 2, uji putaran mesin mobil dilakukan di bengkel mobil yang mempunyai Vehicle Communication Scanner. Pada penelitian ini digunakan Vehicle Communication Scanner type VAUX- COM 120309A dan mobil tahun 2004, kapasitas mesin 1800 cc, bahan bakar bensin, transmisi automatic, sistem bahan bakar injeksi.

Uji putaran mesin dengan perekaman data tegangan listrik pada Vehicle Communication Scanner dilakukan selama 150 detik. Lima puluh detik pertama untuk nilai medan magnet $20 \mu \mathrm{T}$, lima puluh detik kedua untuk nilai medan magnet $40 \mu \mathrm{T}$, lima puluh detik ketiga untuk nilai medan magnet $80 \mu \mathrm{T}$, perekaman dilakukan berulang sebanyak tiga kali. Sebagai pembanding dilakukan satu kali perekaman data putaran mesin pada keadaan normal tanpa perubahan medan magnet akibat kereta api yang lewat.

Pada tahap 3 dilakukan analisis data hasil perekaman putaran mesin kemudian dengan metode uji T untuk sampel berpasangan.

\section{Hasil dan Pembahasan}

\section{A. Data putaran mesin}

Data putaran mesin tanpa dipengaruhi medan magnet

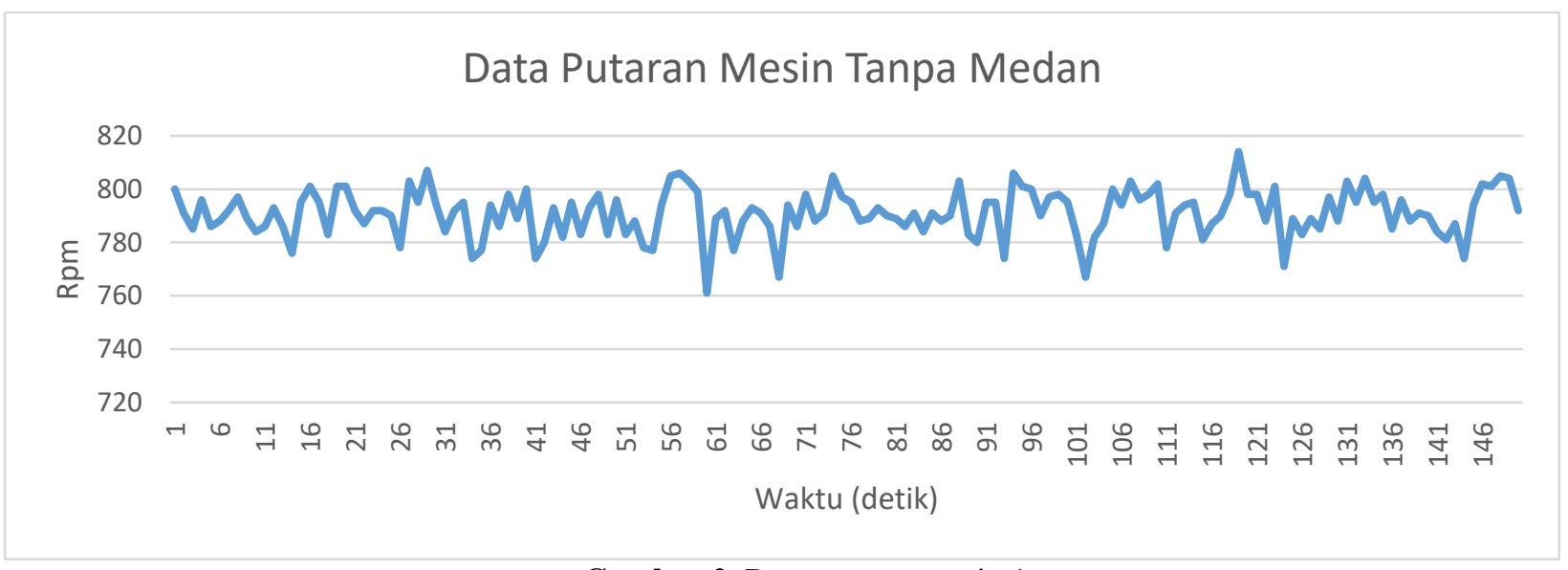

Gambar 2. Data putaran mesin 1

Untuk data putaran mesin tanpa pengaruh medan magnet didapatkan putaran mesin maksimumnya adalah $814 \mathrm{rpm}$ dan minimummnya adalah $741 \mathrm{rpm}$.

Data putaran mesin 1 seperti terlihat pada gambar 3.

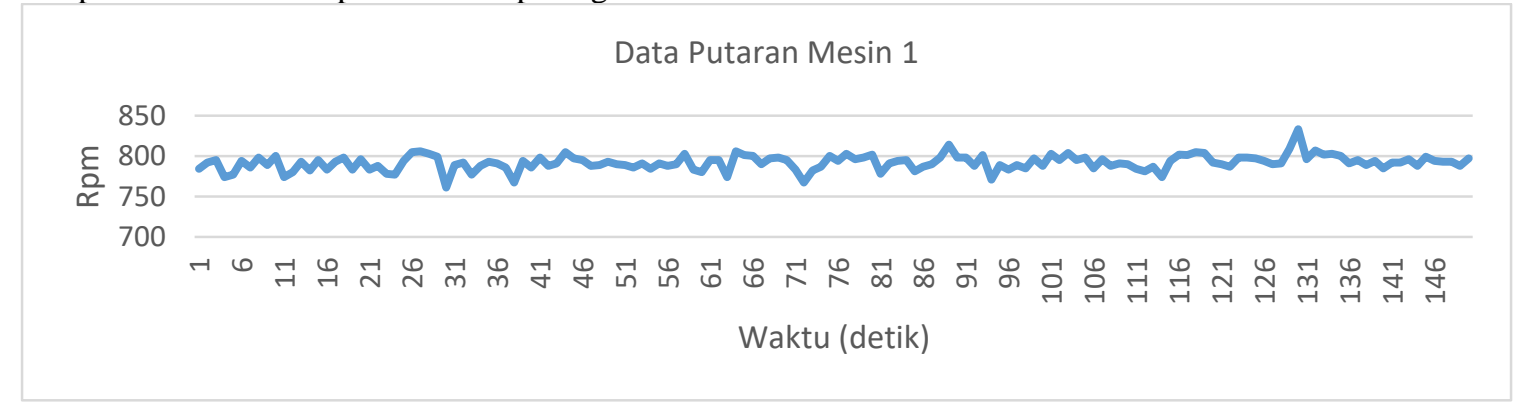

Gambar 3. Data putaran mesin 1 
Procedia of Engineering and Life Science Conference Vol. 1. No. 1 March 2021

Seminar Nasional \& Call Paper Fakultas Sains dan Teknologi (SENASAINS 1 ${ }^{\text {st) }}$

Universitas Muhammadiyah Sidoarjo

Data putaran mesin 2, seperti terlihat pada gambar 4.

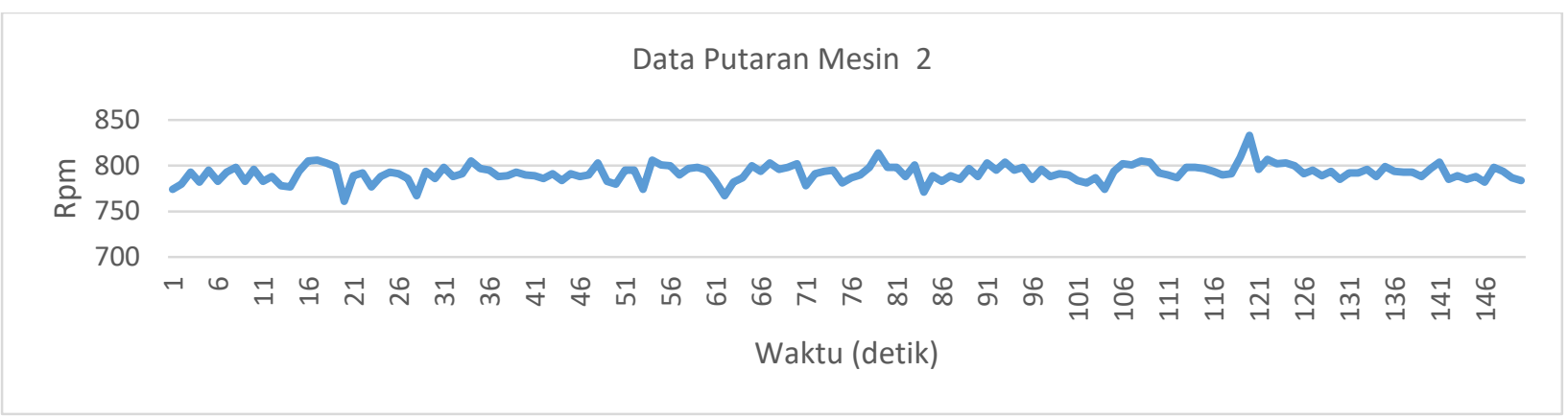

Gambar 4. Data putaran mesin 2

Data putaran mesin 2, seperti terlihat pada gambar 5.

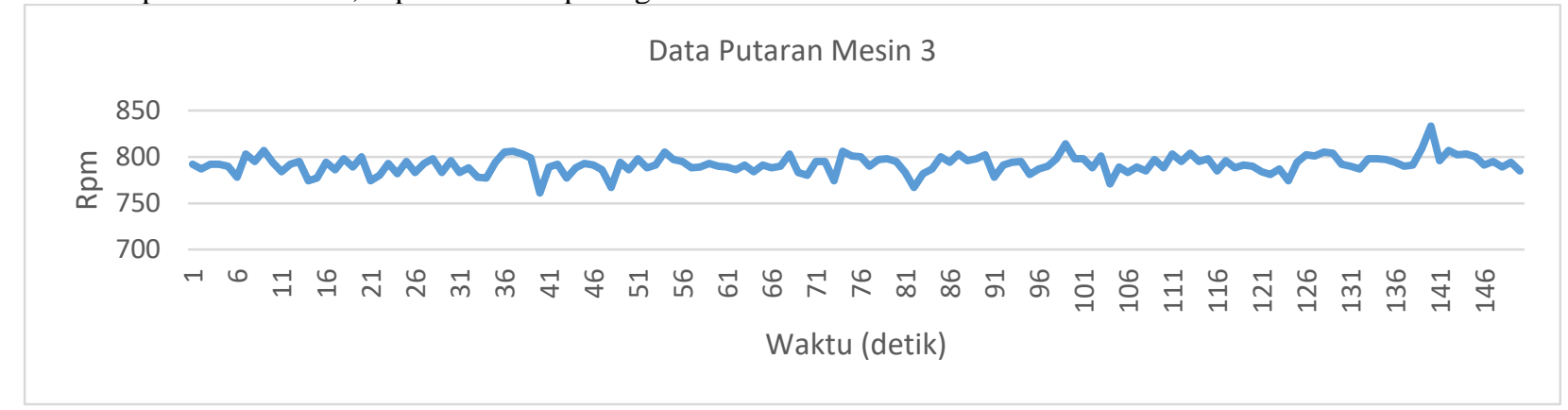

Gambar 5. Data putaran mesin 3

Data ketiga putaran mesin menunjukkan fluktuasi yang berbeda, tetapi sama pada data maksimumnya, yaitu 833 rpm dan minimummnya adalah760 rpm.

\section{B. Analisis Data}

Selanjutnya dilakukan analisis data-data putaran mesin tadi dengan menguji data kelompok data yang tidak dipengaruhi medan magnet dengan kelompok data yang dipengaruh medan magnet menggunakan uji $\mathrm{T}$ untuk dua sampel berpasangan, dengan rumusan hipotesis:

Ho: Data putaran mesin akibat pengaruh perubahan medan magnet $=$ Data putaran mesin tanpa pengaruh perubahan medan magnet bumi

$\mathrm{H}_{1}$ : Data putaran mesin akibat pengaruh perubahan medan magnet $\neq$ Data putaran mesin tanpa pengaruh perubahan medan magnet bumi

.Untuk data putaran mesin 1 diperoleh:

Tabel 2. Hasil uji T untuk data 1

t-Test: Paired Two Sample for Means

\begin{tabular}{lrr}
\hline & $R o$ & $R l$ \\
\hline Mean & 790.96 & 791.8 \\
Variance & 78.62926174 & 88.37583893 \\
Observations & 150 & 150 \\
Pearson Correlation & - & \\
Hypothesized Mean Difference & 0 & \\
df & 149 & \\
t Stat & - & \\
P $(\mathrm{T}<=$ t) one-tail & 0.21558035 & \\
t Critical one-tail & 1.655144534 & \\
P $(\mathrm{T}<=$ t) two-tail & 0.431160701 & \\
t Critical two-tail & 1.976013178 & \\
\hline
\end{tabular}

Untuk data putaran mesin 2 diperoleh: 
Procedia of Engineering and Life Science Conference Vol. 1. No. 1 March 2021

Seminar Nasional \& Call Paper Fakultas Sains dan Teknologi (SENASAINS 1st)

Universitas Muhammadiyah Sidoarjo

Tabel 3. Hasil uji T untuk data 2

t-Test: Paired Two Sample for Means

\begin{tabular}{lrr}
\hline & $R o$ & \multicolumn{1}{c}{$R 2$} \\
\hline Mean & 790.96 & 791.8466667 \\
Variance & 78.62926174 & 86.54680089 \\
Observations & 150 & 150 \\
Pearson Correlation & 0.095357175 & \\
Hypothesized Mean Difference & 0 & \\
df & 149 & \\
t Stat & - & \\
P $(T<=t)$ one-tail & 0.187901237 & \\
t Critical one-tail & 1.655144534 & \\
P $($ T $<$ t) two-tail & 0.375802475 & \\
t Critical two-tail & 1.976013178 & \\
\hline
\end{tabular}

Untuk data putaran mesin 2 diperoleh:

Tabel 4. Hasil uji T untuk data 3

t-Test: Paired Two Sample for Means

\begin{tabular}{lrr}
\hline & \multicolumn{1}{c}{$R o$} & $R 3$ \\
\hline Mean & 790.96 & 791.7866667 \\
Variance & 78.62926174 & 91.43069351 \\
Observations & 150 & 150 \\
Pearson Correlation & - & \\
Hypothesized Mean Difference & 0 & \\
df & 149 & \\
t Stat & -0.76663209 & \\
P $($ T $<$ t) one-tail & 0.222256614 & \\
t Critical one-tail & 1.655144534 & \\
P $($ T $<$ t) two-tail & 0.444513228 & \\
t Critical two-tail & 1.976013178 & \\
\hline
\end{tabular}

Data tabel 1 didapat nilai t hitung: 0.78935 dan nilai t tabel: 1.97601 .

Data tabel 2 didapat nilai t hitung: 0.88831 dan nilai t tabel: 1.97601 .

Data tabel 2 didapat nilai t hitung: 0.76663 dan nilai t tabel: 1.97601.

Dari data hasil uji $\mathrm{T}$ dari ketiga data menunjukkan nilai t hitungnya kurang dari nilai t tabel, sehingga $\mathrm{H}_{1}$ ditolak dan $\mathrm{H}_{0}$ diterima.

\section{KESIMPULAN}

Ditolaknya $\mathrm{H}_{1}$, menyebabkan diterimanya $\mathrm{H}_{0}$ sehingga dapat disimpulkan bahwa perubahan medan magnet bumi tidak mempengaruhi kinerja mesin mobil berbahan bakar bensin terutama terhadap kestabilan putaran mesinnya. Untuk selanjutnya diharapkan ada penelitian lebih lanjut untuk mengetahui penyebab matinya mesin mobil saat melintas di atas rel yang dilewati kereta api.

\section{UCAPAN TERIMA KASIH}

Penulis mengucapkan terima kasih kepada seluruh staf Direktorat Riset dan Pengabdian Masyarakat Direktorat Jenderal Penguatan Riset dan Pengembangan Kementrian Riset, Teknologi dan Pendidikan Tinggi yang telah memberikan dana untuk penelitian ini sesuai dengan kontrak penelitian Nomor: 042 / SP2H / LT- MONO / LL7 / 2020, tanggal 17 Maret 2020. 


\section{REFERENSI}

[1] Rifa Yusya Adilahm. PT KAI: Sepanjang Tahun 2020 Terjadi 198 Kecelakaan di Perlintasan Kereta. [Online].

[2] Penyebab Kecelakaan Kereta Api Didominasi Human Error. Biro Komunikasi dan Informasi Publik - Rabu, 17 Oktober 2012. http://www.dephub.go.id/post/read/penyebab-kecelakaan-kereta-api-didominasi-human-error15056

[3] Ari Purnomo. Mesin Mobil Mati di Atas Pelintasan Kereta Api Disebabkan Medan Magnet, Mitos atau Fakta? [Online]. https://otomotif.kompas.com/read/2020/11/09/063800015/mesin-mobil-mati-di-atas-pelintasan-keretaapi-disebabkan-medan-magnet

[4] Asy. Awas, Medan Magnet Rel KA Bisa Mogokkan Kendaraan Anda. detikNews. Kamis, 04 Nov 2004 10:30 WIB. [Online]. https://news.detik.com/berita/d-235916/awas-medan-magnet-rel-ka-bisa-mogokkan-kendaraananda

[5] AS Fauzi. Medan Magnet di Sekitar Rel Kereta Api. Jurnal Mesin Nusantara. Vol 2. No 1. 27-33. 2019. https://ojs.unpkediri.ac.id/index.php/JMN/article/view/13134

[6] Syamsul Hidayat Lubis, Sutisno, Litanya Oktonovrilna. Analisa Gangguan Medan Magnet Kereta Api Listrik terhadap Pengamatan Geomagnet. AL-FIZIYA Vol I, No 2, Oktober 2018.

[7] Finlay, C. dkk., "International Geomagnetic Reference Field: the eleventh generation". Geophysical Journal International. 183 (3): 1216-1230 (December 2010).

[8] Muhamad Ivan Anugrah, Vina Serevina, Hadi Nasbey. Pengembangan Alat Praktikum Medan Magnet Sebagai Media Pembelajaran Fisika SMA. Prosiding Seminar Nasional Fisika (E-Journal) SNF2015. Volume IV, Oktober 2015 e-ISSN: 2476-9398; p-ISSN: 2339-0654

[9] Sudirman Lubis, Analisa Tegangan Keluaran Alternator Mobil Sebagai Pembangkit Energi Listrik Alternatif, RELE (Rekayasa Elektrikal dan Energi). Jurnal Teknik Elektro. Vol 1. No 1 (2018). E-ISSN 2622-7002.

[10]Reka Harnis. Kelistrikan Mobil Bermasalah? Bukan Cuma Aki Penyebabnya. June 12, 2020. [Online]. https://www.seva.id/blog/kelistrikan-mobil-bermasalah-bukan-cuma-aki-penyebabnya-062020/2/

[11] Mikrajuddin Abdullah. E-BOOK Fisika Dasar II. ITB. 2017 